\title{
Is it Possible to Maximize Return on Investment and Achieve Adequate Market Share at the Same Time?
}

\author{
Sharfuddin Ahmed Khan* \\ Industrial Engineering \& Engineering Management Department, University of Sharjah, Sharjah, UAE
}

\begin{abstract}
Nowadays due to high competition, organizations are looking to increase their market share but at the same time, they want quick return on investment (ROI). This article will define the basis of ROI and market share and try to find the relationship between them. At the end we will be able to answer the question "Is it Possible to Maximize Return on Investment and Achieve Adequate Market Share at the same time?"
\end{abstract}

\section{Introduction}

Return on Investment (ROI) is one of the most popular performance measurement and evaluation metrics used in business analysis. ROI analysis (when applied correctly) is a powerful tool for evaluating existing information systems and making informed decisions on software acquisitions and other projects [1]. According to the Investopedia, ROI is a performance measure used to evaluate the efficiency of an investment or to compare the efficiency of a number of different investments. To calculate ROI, the benefit (return) of an investment is divided by the cost of the investment; the result is expressed as a percentage or a ratio [2].

ROI is a simple financial tool that measures the economic return of a project or investment. Similarly, market share is the percentage of total industry sales that an organization is responsible for. For instance, XYZ Co. has $\$ 10$ million in sales in the widget industry, which has a total of $\$ 100$ million in sales from all companies in the industry. So, XYZ has a $10 \%$ market share. Market share is the percentage of a market (defined in terms of either units or revenue) accounted for by a specific entity." In a survey of nearly 200 senior marketing managers, $67 \%$ responded that they found the "dollar market share" metric very useful, while $61 \%$ found "unit market share" very useful [3].

Many organizations are looking for higher market share if they study market properly and their method of pricing is suitable for market leaders. Market share measures the effectiveness of the investment by calculating how many times the net benefits recover the original investment.

\section{Possible to Achieve both "Maximize ROI" \& "Achieving Adequate Market Share?"}

Maximizing ROI refers to getting the largest percentage of profit possible. Whereas increasing market share would likely involve a lowering of prices in order to gain added market. The economics of this is that it would result in a reduced ROI. This is what theory says. But in reality, things may be different so to answer the question of whether it is possible to maximize ROI and increase market share at the same time. I would say "Yes."

But in order for this to be true, following factors would need to come in play.

- Size of the company.

- The particular market that the company is going after.

- The time period over which the ROI is measured.

\section{Reasons why normally can't achieve both?}

There are many reasons that organizations are failed to achieve both. Some of the reasons are mentioned below.

a. There is an inversely relationship between the market share and ROI (Figure 1).

b. Market share increases as ROI decreases.

c. The lower prices helped enhance share and at the same time increased the primary demand for the company products as LAW OF DEMAND says.

d. Market share depends on price of product and ROI depends on unit profit of product (Figure 2).

e. Maximizing ROI refers to getting the largest percentage of profit possible (Figure 3).

f. Increasing market share would likely involve a lowering of prices in order to gain added market.

g. The price strategy selected by the firm is naturally dependent on the objectives the firm has chosen to pursue.

h. If the \% ROI is little less than the required \%ROI, we may increase the product price to reach an adequate level.

i. Profit maximization may call for higher prices through changing what the market can bear. Enhancing market share on the other hand may require a low price policy designed to penetrate new or exciting market.

j. Once an appropriate price and market size is know we can find the relevant ROI.

\section{Conclusion}

Above study shows that it is possible for an organization to

*Corresponding author: Sharfuddin Ahmed Khan, Industrial Engineering \& Engineering Management Department, University of Sharjah, Sharjah, UAE, Tel: 971552563074; E-mail: skhan@sharjah.ac.ae

Received October 08, 2014; Accepted October 13, 2014; Published October 20 2014

Citation: Khan SA (2014) Is it Possible to Maximize Return on Investment and Achieve Adequate Market Share at the Same Time? Ind Eng Manage 3: 141. doi: 10.4172/2169-0316.1000141

Copyright: (C) 2014 Khan SA. This is an open-access article distributed under the terms of the Creative Commons Attribution License, which permits unrestricted use, distribution, and reproduction in any medium, provided the original author and source are credited. 


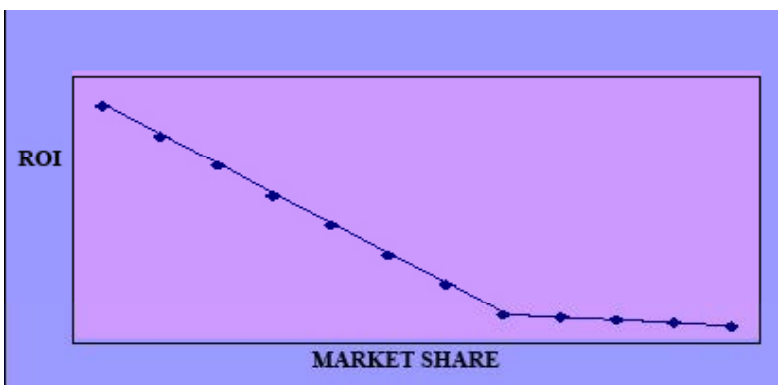

Figure 1: Graph showing ROI and Market Share.

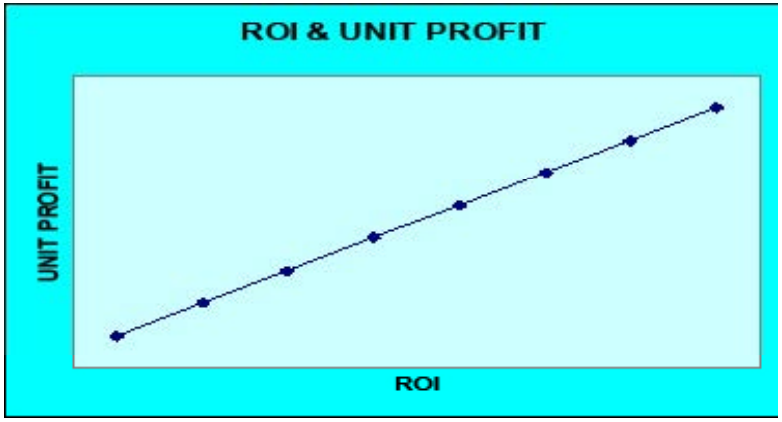

Figure 2: Graph showing ROI and Unit Profit.

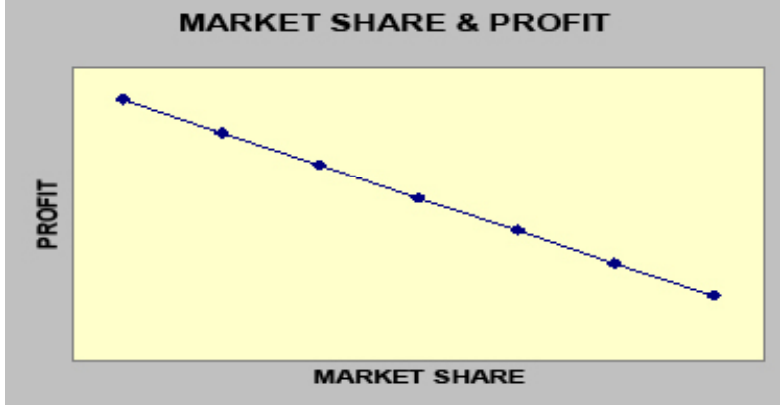

Figure 3: Graph showing Market Share and Profit.

maximize their ROI and at the same time it is quite possible that they can achieve adequate market share. In order to attain this situation, organizations should pay extra attentions on certain factors such as product price, pricing strategy, relationship between ROI and product price and unit profit of product.

\section{References}

1. Botchkarev A, Andru P (2011) A Return on Investment as a Metric for Evaluating Information Systems: Taxonomy and Application. Interdisciplinary Journal of Information, Knowledge, and Management 6: 245-269.

2. Return on investment - ROI. (2011) In Investopedia .Retrieved October $6^{\text {th }}$ 2014

3. Farris P, Neil T, Phillip E, David J (2010) Marketing Metrics: The Definitive Guide to Measuring Marketing Performance. (2ndedn) Upper Saddle River, New Jersey: Pearson Education, Inc. ISBN 0137058292. 